\title{
Long-Term Care Financing
}

An estimated 12 million people in the United States currently need longterm care. ${ }^{1}$ In the United States, long-term care is often referred to as long-term services and supports (LTSS), which include healthcare and assistance with activities of daily living (ADLs). ${ }^{2}$ Some common services and supports include caregiver assistance, nursing home care, adult daycare, home health and personal assistance, and transportation. By 2050, the number of those needing long-term care is projected to more than double to 27 million $^{3}$ (Fig. 3.1). Nearly 70 percent of those 65 and older will need some form of long-term care in their lifetime, ${ }^{4}$ and 20 percent will need it for five or more years. ${ }^{5}$ The annual cost of long-term care today is approximately US $\$ 725$ billion. ${ }^{6}$ As the population continues to age, healthcare costs could potentially reach unsustainable levels. Medicaid estimates that their spending on LTSS will increase six percent annually through $2021 .^{7}$ When the baby boom generation ${ }^{8}$ begins to reach age 85 in 2030, the spending growth for LTSS will be further accelerated and will represent three percent of the GDP. ${ }^{9}$ The percentage of GDP of public long-term care expenditures of the OECD countries is projected to grow from 0.8 in 2010 to 1.6 in 2060. For the BRIICS countries (Brazil, 


\section{DEMAND FOR LONG-TERM SERVICES AND SUPPORTS [LTSS] WILL GROW DRAMATICALLY}

\section{2

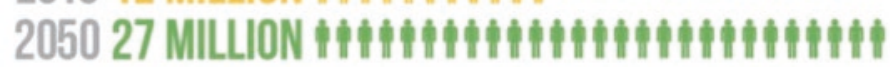

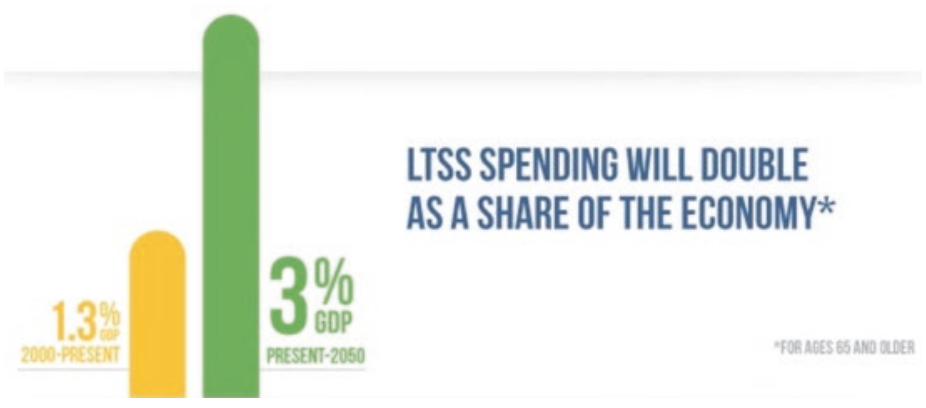

Fig. 3.1 Growth in demand for LTSS. Source: Bipartisan Policy Center

Russia, India, Indonesia, China, and South Africa), the growth projection of long-term care expenditures is from 0.1 to 0.9 percent of GDP. ${ }^{10}$

Managed care and home-based care are two trends that can lower costs and improve care. Government-funded Medicaid contracts with managed care organizations and pays a monthly capitated payment per patient. As described in Chap. 1, this value-based care reimbursement arrangement is an incentive for healthcare systems to be efficiently integrated and provide higher-quality, lower-cost care. As mentioned previously, in an effort to lower costs and improve quality of life for older patients, health providers are moving toward person-centered homebased models and away from institutional care. This trend is also taking place globally. Other housing models that can contribute to lower LTSS costs are neighborhoods such as villages (V2V) and naturally occurring retirement communities (NORCs), where residents receive care and support collectively. We will describe these housing models in Chap. 7.

Even with better emerging delivery and reimbursement models, health systems around the world are facing challenges in financing higherquality, lower-cost long-term services and supports for their older citizens. 


\section{Global Funding Goals}

The global demographic shift indicates that many nations around the world are faced with the pressing need of financially sustainable health systems to provide long-term care. Lower- and middle-income countries are less prepared to address the need. Global data regarding the lack of access to long-term care exists only on a national level, and according to the World Health Organization, it "reveals large gaps in the provision of and access to such services in many low and middle-income countries." 11

AARP distilled the common goals of developed countries with differing models of long-term care financing and health and service delivery that include ${ }^{12}$ :

- Providing "consumer-directed" home care and programs to enhance choice and independence;

- Encouraging home and community-based services rather than institutional care;

- Encouraging family support of persons with disabilities;

- Providing universal coverage for long-term care services;

- Insuring individuals against the high costs of long-term care through a mix of public and private financing;

- Improving the coordination between chronic medical care and longterm care services.

\section{Barriers to Sustainable Long-Term Care Financing in the United States}

\section{Public Knowledge}

Most Americans do not know how the long-term care system operates. As a result, they do not support financing reforms that would make supporting long-term care possible. ${ }^{13}$ The citizens of the United States must be educated about the existing long-term care system or the much-needed 
reform will not happen. Lack of knowledge of the long-term care system, along with denial, leaves many unprepared for the costs that they will likely incur in old age.

Long-term care expenses are one of the greater economic risks that older Americans face. (Richard Johnson, former director, Urban Institute, Program on Retirement Policy) ${ }^{14}$

\section{Cost}

Not everyone can afford private long-term care insurance. The annual cost of a policy for a couple at age 55 can range from US\$2085 to US $\$ 3970$, depending on the insurer, the policy purchased, and health profile of the purchaser. ${ }^{15}$ Long-term care insurance has inherent risks to the policyholder who may not be able to continue paying every year. When beneficiaries let their policies lapse, the annual premiums that they may have paid for decades is lost, and will not be available to pay for their future care.

\section{Reimbursement Policy}

Medicare and private insurers do not reimburse for long-term nursing home stay. In 2016, the average annual cost of nursing home care ranged from approximately US\$82,128 for a semiprivate room to US\$92,376 for a private room. ${ }^{16}$ On average, people will need three years of longterm care in their lifetime. ${ }^{17}$ The beneficiaries will also realize high out-ofpocket expenses related to long-term care. These costs are not affordable by most. ${ }^{18}$ Many are forced to spend down their savings and sell their homes.

Only after a person has depleted almost all of their savings will they be eligible for long-term care reimbursement from Medicaid. Medicaid is a means and or disability tested, joint federal and state government financed healthcare insurance that covers home care, assisted living, and skilled nursing care. The process of obtaining Medicaid at this stage is complicated 
and difficult for older individuals to navigate. Additionally, asset depletion can leave a surviving spouse and or family in financial ruin.

Another option for lower-income families is to keep the older relative at home and become the informal caregiver. This option places physical and emotional strain on the caregiver, who is most often an older female living with health challenges of her own. Many countries have recognized the integral role of the informal caregiver in enabling a person to remain at home and the considerable financial value this care brings to the health system. Recognition has come in the form of paid leave (care leave), respite support, ${ }^{19}$ and financial reimbursement.

Veterans in the United States receive a pension and some support with homecare and assisted living. The combination makes long-term care affordable by most veterans but not without out-of-pocket costs.

\section{Long-Term Care Insurance}

With the present and rapidly growing need for long-term care, one would expect that the long-term care insurance industry in the United States would be thriving. In his interview, insurance expert Claude Thau reveals that it is anything but.

\section{Claude Thau, Thau Incorporated}

Claude Thau is the president of Thau Incorporated, which provides consulting services to insurers, employers, regulators, and businesses that offer services to the long-term care insurance industry.

It would be tempting to assume that the long-term care insurance industry is suffering due to the fact that Americans are living longer with higher rates of comorbidity, healthcare costs are rising, and the cost of medications are skyrocketing. Surprisingly, these are not the main reasons the industry is struggling.

In the 1980s, many insurers in the United States began to offer private long-term policies. It was a new product for insurers and they did not have adequate data to accurately calculate risk. Claude explained that the 
two most critical measures of risk factors were interest rates and lapse rates.

No one could have possibly anticipated the investment income yield climates we have experienced in the last decade.

When insurers receive premium payments, they place those funds in interest earning accounts. Most of the money insurers use to pay longterm care claims comes from the interest earned because insurers set aside large reserves (to remain solvent) for a long time in support of long-term care insurance policies. In the mid- to late 1990s, actuaries were assuming that these accounts would earn seven percent net income. Interest rates in the United States dropped to historic lows, causing insurers to be short by three to four percent annually. The low insurance rates dealt a powerful blow to long-term care insurers, but the unpredictably low lapse rate caused an even bigger problem.

A one percent difference in lapse rate hurts profits as much as one percent reduction in investment income.

When an insured person does not continue to pay their premiums, their policy lapses. When the policy lapses, all of the reserve that the insurance company has set aside over the years can be released. The insurer accumulated payments, but will not bear the responsibility of paying for expensive long-term care for the person whose policy lapsed. The released reserves can be used to pay for future claims of policyholders who kept up to date with their premium payments or become profit.

If, when determining the price for long-term care insurance, insurers ignored the possibility that people would let their policies lapse, the prices would be higher and the insurers would reap large benefits when policies lapsed. To avoid that situation and provide a better deal to consumers, insurers reflect expected lapses when pricing policies.

In the mid-1990s, reinsurers, companies that insure insurance companies, recommended that insurers assume an eight percent lapse rate each year after the first two years a policy was in place. This was a fateful rec- 
ommendation. The actual lapse rate was seven tenths of a percent, leaving insurers with the responsibility of paying for many more beneficiaries than they had anticipated. By 2010, insurers had four times as many policies in effect than they had predicted. This dramatically increased the amount of claims insurers had to reimburse. Claude explained that the higher priced policies of today are adjusted to assume a more accurate interest and lapse rate prediction.

Based on our research, we believe current policies are too expensive for many individuals. This highlights the need for individual, public, and private involvement to advocate for financing policy that includes universal health coverage for the millions of Americans who will need long-term care. In this arena, America has a lot to learn from other developed countries.

In our next chapter, we write about long-term care that is personcentered and organizationally efficient. The methods and models are a glimmer of hope for the possibility of reducing long-term care costs and improving health outcomes and quality of life for those living in long-term care residences.

The full interview of Claude Thau can be found at this link: www. accessh.org/agingwell.

\section{Notes}

1. Bipartisan Policy Center (2014). America's long-term care crisis: Challenges in financing and delivery. https://bipartisanpolicy.org/ library/americas-long-term-care-crisis/. Accessed April 2017.

2. Activities of daily living include: toileting, bathing, dressing, eating, transferring out of bed, incontinence care, meal preparation, housekeeping, and medication management.

3. Ibid.

4. U.S. Department of Health and Human Services. https://longtermcare. acl.gov/the-basics/. Accessed April 2017.

5. Ramanarace, C. (2011). 10 misconceptions about long-term care insurance. AARP Medical Resource Center. http://www.aarp.org/health/ medicare-insurance/info-10-2011/long-term-care-insurancemisconceptions.html. Accessed April 2017. 
6. The Scan Foundation. http://www.thescanfoundation.org/publications? keys $=\&$ field_article_categories_tid=All\&field_series_tid $=512$. Accessed April 2017.

7. Bipartisan Policy Center (2014). America's long-term care crisis: Challenges in financing and delivery. https://bipartisanpolicy.org/ library/americas-long-term-care-crisis/. Accessed April 2017.

8. People born between 1946 and 1964 .

9. Ibid.

10. OECD. Public spending on health and long-term care: a new set of projections. http://www.oecd.org/eco/growth/public-spending-onhealth-and-long-term-care.htm. Accessed April 2017.

11. World Health Organization. Ageing and life-course. Long-term care systems. http://www.who.int/ageing/long-term-care/en/. Accessed April 2017.

12. Gibson, M.J., Gregory, S.R. \& Pandya, S.M. (2003). Long-term care in developed nations: A brief overview. AARP. http://assets.aarp.org/rgcenter/health/2003_13_ltc_dv.pdf. Accessed April 2017.

13. Wiener, J. (2017). Long-term care financing reform: Can we get there from here? https://www.linkedin.com/pulse/long-term-carefinancing-reform-can-we-get-from-here-joshua-wiener. Accessed April 2017.

14. http://www.urban.org/policy-centers/cross-center-initiatives/programretirement-policy. Accessed April 2017.

15. American Association for Long-Term Care Insurance. How much does long-term care insurance cost? http://www.aaltci.org/long-term-careinsurance/learning-center/how-much-does-long-term-care-insurancecost.php. Accessed April 2017.

16. Genworth. Compare long-term care costs across the United States. https://www.genworth.com/about-us/industry-expertise/cost-of-care. html. Accessed April 2017.

17. Ramanarace, C. (2011). 10 misconceptions about long-term care insurance. AARP Medical Resource Center. http://www.aarp.org/health/medicare-insurance/info-10-2011/long-term-care-insurance-misconceptions. html. Accessed April 2017.

18. Cubanski, J., Casillas, G., \& Damico, A. (2015). Poverty among seniors: An updated analysis of national and state level poverty rates under the official and supplemental poverty measures. Kaiser Family Foundation. 
19. Interventions that provide temporary breaks for the caregivers that are meant to ensure that the caregiver will be able to maintain care responsibilities.

Open Access This chapter is licensed under the terms of the Creative Commons Attribution 4.0 International License (http://creativecommons.org/licenses/ by/4.0/), which permits use, sharing, adaptation, distribution and reproduction in any medium or format, as long as you give appropriate credit to the original author(s) and the source, provide a link to the Creative Commons licence and indicate if changes were made.

The images or other third party material in this chapter are included in the chapter's Creative Commons licence, unless indicated otherwise in a credit line to the material. If material is not included in the chapter's Creative Commons licence and your intended use is not permitted by statutory regulation or exceeds the permitted use, you will need to obtain permission directly from the copyright holder.

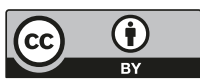

